\title{
Configural Cue Performance in Identical Twins Discordant for Posttraumatic Stress Disorder: Theoretical Implications for the Role of Hippocampal Function
}

\section{Citation}

Gilbertson, Mark W., Stephanie K. Williston, Lynn A. Paulus, Natasha B. Lasko, Tamara V. Gurvits, Martha E. Shenton, Roger K. Pitman, and Scott P. Orr. 2007. "Configural Cue Performance in Identical Twins Discordant for Posttraumatic Stress Disorder: Theoretical Implications for the Role of Hippocampal Function." Biological Psychiatry 62 (5) (September): 513-520. doi:10.1016/j.biopsych.2006.12.023.

\section{Published Version}

doi:10.1016/j.biopsych.2006.12.023

\section{Permanent link}

http://nrs.harvard.edu/urn-3:HUL.InstRepos:28552565

\section{Terms of Use}

This article was downloaded from Harvard University's DASH repository, and is made available under the terms and conditions applicable to Other Posted Material, as set forth at http:// nrs.harvard.edu/urn-3:HUL.InstRepos:dash.current.terms-of-use\#LAA

\section{Share Your Story}

The Harvard community has made this article openly available.

Please share how this access benefits you. Submit a story.

\section{Accessibility}




\title{
Configural Cue Performance in Identical Twins Discordant for Posttraumatic Stress Disorder: Theoretical Implications for the Role of Hippocampal Function
}

\author{
Mark W. Gilbertson, Stephanie K. Williston, Lynn A. Paulus, Natasha B. Lasko, Tamara V. \\ Gurvits, Martha E. Shenton, Roger K. Pitman, and Scott P. Orr \\ Manchester VA Medical Center (MWG, SKW, LAP, NBL, TVG, SPO), Manchester, New Hampshire; \\ Harvard Medical School (MWG, NBL, TVG, MES, RKP, SPO); Massachusetts General Hospital \\ (RKP), Boston; and the VA Boston Healthcare System (MES), Brockton, Massachusetts.
}

\begin{abstract}
Background-A significant subgroup of individuals with posttraumatic stress disorder (PTSD) exhibits chronic, unremitting symptomatology that has also been associated with smaller hippocampal volume. The hippocampus plays a significant role in configural processing of contextual cues that facilitates context-appropriate extinction of conditioned fear. We test the hypothesis that hippocampus-based configural processing deficits are a pre-existing vulnerability factor for unremitting forms of PTSD.
\end{abstract}

Methods-Participants included male monozygotic twin pairs who were discordant for combat trauma. In 18 twin pairs the combat-exposed brother developed unremitting PTSD, whereas in 23 pairs the combat-exposed brother never developed PTSD. Participants were compared in the capacity to solve allocentric spatial processing tasks, and this performance was examined for its relationship to the severity of PTSD symptomatology and hippocampal volume.

Results-Although not completely differentiated from overall IQ, PTSD combat veterans demonstrated significantly impaired performance in configural processing relative to non-PTSD combat veterans. Despite having neither combat-exposure nor PTSD, the unexposed co-twins of combat veterans with PTSD displayed the same decrements as their brothers. Deficits were significantly related to PTSD severity and hippocampal volume.

Conclusions-The current study provides the first evidence that the relevance of the hippocampus in PTSD might be related to pre-existing configural cue processing deficits that predispose individuals to develop unremitting forms of the disorder.

\section{Keywords}

Configural; contextual; hippocampus; neuropsychology; PTSD; twins

Posttraumatic stress disorder (PTSD) includes a constellation of disabling behavioral and emotional symptoms that occur in a proportion of individuals exposed to severe psychological trauma. Although many individuals with PTSD show remission within the first year after traumatic exposure, a significant subgroup of PTSD patients-perhaps as high as 30\%-40\% (Kessler et al. 1995)—demonstrates an unremitting course of illness that might persist for many 
years or decades. Furthermore, individuals diagnosed with chronic PTSD have shown the ability to maintain conditioned fear responses to traumatic stimuli 40-50 years after an event (Orr et al. 1993). A number of factors might impact the development of chronic PTSD, including severity of trauma, level of social support, and the presence of anger or depression (Koenen et al. 2003). It is unclear to what degree biological factors might also influence the course or chronicity of PTSD-related emotional responses.

Smaller hippocampal volume has been a frequently replicated finding in the PTSD literature. Magnetic resonance imaging (MRI) studies of hippocampal volume in human subjects have established a relatively consistent pattern showing smaller hippocampi in individuals diagnosed with PTSD (Bremner et al. 1995a, 1997; Gilbertson et al. 2002; Gurvits et al. 1996; Stein et al. 1997; Villarreal et al. 2002). These imaging studies have largely employed subjects with severe and unremitting courses of illness (i.e., combat veterans or childhood abuse survivors who continue to report significant symptomatology for many years). We have specifically reported (Gilbertson et al. 2002) that hippocampal volume differences in PTSD might be most relevant to those individuals who maintain severity scores $>65$ on the ClinicianAdministered PTSD Scale (CAPS) for many years after the traumatic event. Studies failing to find hippocampal differences in PTSD have often employed less severe and/or less chronic populations of subjects (Bonne et al. 2001; Carrion et al. 2001; De Bellis et al. 1999, 2001). These findings suggest the possibility that hippocampal volume might be more relevant to the course of PTSD than to the development of PTSD per se (i.e., smaller hippocampal volume might be associated with a more severe and unremitting course of illness). An understanding of the mechanism through which smaller hippocampal volume might influence the development and course of PTSD remains unclear.

In humans, the hippocampus has been frequently linked to declarative memory function (Squire 1992; Zola-Morgan and Squire 1993). Verbal memory impairments have often been reported in PTSD (Beers and De Bellis 2002; Bremner et al. 1993, 1995b; Gilbertson et al. 1997, 2001; Golier et al. 2002; Horner and Hamner 2002; Vasterling et al. 1998, 2002; Yehuda et al. 1995). Such impairments, however, do not readily lend themselves to an explanation of chronicity or the disorder's core clinical phenomenology, which includes excessive memory retrieval and intrusive, context-inappropriate emotional responding. Studies of patients with chronic PTSD have often failed to find a specific relationship between declarative memory and hippocampal volume (Bremner et al. 1997; Gurvits et al. 1996; Stein et al. 1997) or have instead suggested that these deficits might represent prefrontal lobe contributions (Vasterling et al. 1998; 2002).

There is an emerging picture in the animal literature of the hippocampus as a critical site for the processing of contextual information, particularly as it relates to fear-mediated learning (Corcoran and Maren 2001; McDonald et al. 2002; Moses et al. 2002; Phillips and LeDoux 1992; Selden et al. 1991). Animals acquire conditioned responses not only to a discrete conditioned stimulus (CS; e.g., tone) that is paired with an unconditioned stimulus (US; e.g., foot shock) but also to more complex contextual cues in the external environment that surround the CS-US pairing (Holland and Bouton 1999; Maren et al. 1997; Phillips and LeDoux 1992; Selden et al. 1991). The hippocampus has been shown to be especially relevant to the mediation of spatial cues that have the quality of being allocentric (i.e., processing of configural relationships among distal environmental features) as opposed to egocentric (i.e., processing merely in reference to the organism's midline axis) (Astur et al. 2002; Burgess et al. 1999; Driscoll et al. 2003; Incisa della Rocchetta et al. 2004). Complex arrays of distal contextual cues might serve as configural "signals" for identifying when the environment is related to the original conditioned fear response (i.e., has a "dangerous" or "safe" context) and hence whether a fear response should be emitted. Animal studies have demonstrated that configural processing of environmental cues might play a significant role in discriminative fear conditioning and 
extinction, with impairments in this type of contextual skill having been shown to impede the extinction of conditioned fear responses (Frankland et al. 1998; Maren, 2001). If individuals with PTSD exhibit basic deficits in allocentric processing capacity, this might provide preliminary evidence for a potential model of hippocampal function in PTSD that can improve our understanding of the chronic and unremitting emotional responses observed in the disorder.

Most neuropsychological studies of PTSD have not employed allocentric-based spatial tasks. Standard visuospatial tasks such as recognition or recall of complex shapes are primarily egocentric in nature (i.e., encoded in reference to the midline axis of the participant's body). Cognitive studies have not consistently found PTSD-related deficits in such standardized tests of visuospatial function (Gilbertson et al. 2001, 2006; Horner and Hamner 2002; Vasterling et al. 1998, 2002). Some findings have seemed suggestive of allocentric-like spatial difficulties, including impairments in the copying of three-dimensional figures (Gurvits et al. 2000, 2002) or single block rotation errors on Wechsler Adult Intelligence Scale-Revised (WAISR) Block Design (Vasterling et al. 2000). However, such tasks can be solved with egocentric processing alone and were not designed as primary allocentric measures.

Employing a sample of monozygotic twin pairs discordant for combat exposure (Gilbertson, et al. 2002, 2006), we examined a task that emphasizes allocentric spatial processing. We attempted to test two hypotheses: 1) do individuals with PTSD demonstrate hippocampusbased impairment in the allocentric encoding of configural relationships among cues; and 2) if such a deficit exists, does it serve as a vulnerability factor for the development of more chronic forms of PTSD?

\section{Methods and Materials}

\section{Participants}

Rationale-Participants included male monozygotic twin pairs in which one brother served in combat during the Vietnam War (exposed, Ex) and his identical co-twin did not (unexposed, Ux). On the basis of the diagnosis of the combat-exposed brother, twin pairs were classified into two groups: chronic PTSD (P+) and non-PTSD (i.e., never had) (P-). The P+ or Pdesignation refers to the combat-related PTSD status of the exposed twin (no unexposed cotwin in this study had non-combat-related PTSD). Combat-unexposed brothers will also be referred to as high-risk (UxP+) versus low-risk (UxP-) co-twins on the basis of whether or not their combat-exposed brother developed PTSD. Differences in cognitive performance between brothers might be interpreted as evidence for unique environmental effects (e.g., stress-induced toxicity related to combat). Differences in performance between the (high-risk) unexposed brothers of PTSD combat veterans and the (low-risk) unexposed brothers of non-PTSD combat veterans provide evidence for familial, probably pre-existing, traits.

Sample Recruitment-Participants were recruited with the assistance of the Vietnam Era Twin (VET) Registry, which determined zygosity (Eisen et al. 1989) and combat status (via military records) of each twin pair. Combat severity in the Ex twin was assessed with a standard 18-item combat exposure measure (Janes et al. 1991). A full description of the recruitment strategy appears elsewhere (Gilbertson et al. 2002, 2006; Orr et al. 2003).

The study protocol was reviewed and approved by the Veterans Affairs Medical Center (Manchester, New Hampshire) Institutional Review Board and Human Subjects Subcommittee. After a full explanation of the procedures, all individuals provided written informed consent before participation. The PTSD diagnostic status of combat-exposed twins and their overall PTSD symptom severity were determined by an experienced doctoral-level psychologist (NBL) with CAPS (Blake et al. 1995). All participants completed a Stressful Life Events Checklist (available upon request) designed to quantify the lifetime number of non- 
combat events that potentially met DSM-IV PTSD A (stressor) criterion. All participants were interviewed with the Structured Clinical Interview for DSM-IV (SCID; First et al. 1994) to determine the presence of other Axis I mental disorders. The Michigan Alcoholism Screening Test (MAST; Selzer 1971) was employed as a measure of prior alcohol abuse.

Combat veterans with past but not current PTSD were excluded. No participants met DSM-IV criteria for a psychotic or bipolar disorder or non-combat-related PTSD. Owing to high comorbidity of major depression and substance use disorders with PTSD, these disorders were not exclusionary. Likewise, individuals reporting current psychotropic medication usage were not excluded from participation. Issues of comorbidity and medication use have been addressed statistically in this sample and reported in detail previously (Gilbertson et al. 2006). History of major neurologic disorder or significant abnormality discovered upon MRI scan (e.g., tumor) resulted in exclusion of two participants. Owing to a scheduling conflict and an acute medical condition, two participants were unable to complete neuropsychological testing. Data from both members of a twin pair were excluded from the analyses if either member was excluded. The final sample comprised 18 PTSD twin pairs and 23 non-PTSD twin pairs. Demographic and clinical characteristics of the sample appear in Table 1.

\section{Configural Cue Processing}

Patterned after a task described by Halpern (1986) and French et al. (1963), a "Cube and Paper Test" was constructed by the first author in an effort to assess the ability to mentally manipulate allocentric spatial cues. The Cube and Paper Test provides an untimed measure of visuospatial function in a multiple-choice format without a praxic component. The task is allocentric in nature (i.e., dependent upon configural relationships to neighboring stimuli and cannot be solved by merely referencing the midline axis of the participant). It is composed of 20 items of two types (see sample items in Figure 1). In one set of items, subjects are asked to imagine a piece of paper being folded and a series of holes being punched through all layers of the folded paper. Subjects are then asked to select the correct configural pattern of holes when the paper is unfolded. The second set of items is composed of cubes that contain markings (e.g., letters, numbers, geometric shapes) on each face, with the restriction that no item appears on more than one face of a given cube. Subjects are asked to examine a target cube and then select the cube among several alternatives that could be a different (rotated) view of the target cube. The two item types represent visuospatial constructs that are considered differentiable (McGee 1979) (i.e., "orientation" [cube rotation] and "visualization" [paper folding]), but the historic and empiric description of these two constructs both fall within the concept of "allocentric" processing as described here. We found the two item types to be highly and significantly intercorrelated within our sample, and the major analyses conducted in the current study found no differences dependent upon item type. Thus, the items were collapsed into a single measure with the total number of errors in the 20 -item task serving as the dependent variable.

The Cube and Paper Test was administered as part of a larger cognitive assessment battery employing more standard measures of neuropsychological function (Gilbertson et al. 2006). It was therefore possible to compare performance on the Cube and Paper Test with more standard measures of visuospatial function that are not allocentric in nature. These measures included the Block Design from the WAIS-R (Wechsler 1987), the Benton Facial Recognition Task (FRT; Benton and Van Allen 1973), and the Visual Object and Spatial Perception test (VOSP; Warrington and James 1991). Results of the California Verbal Learning Test (CVLT; Delis et al. 1987), a measure of verbal declarative memory, were also available for comparison, as was an overall measure of estimated IQ (Gilbertson et al. 2006). 


\section{Hippocampus Volume: MRI Image Acquisition and Volumetric Analyses}

Results of volumetric analyses of the twin sample studied here have been previously reported (Gilbertson et al. 2002), as have the specific imaging techniques employed (Gurvits et al. 1996; Shenton et al. 1992). Total hippocampal volume was therefore available for correlation with performance on the Cube and Paper Test.

\section{Statistical Analysis}

Demographic and psychometric data were analyzed by means of a mixed model that treated PTSD Diagnosis (i.e., chronic combat-related PTSD vs. non-PTSD in the combat-exposed twin) as a between-pairs fixed effect, Combat Exposure (presence or absence) as a within-pair fixed effect, and twin pairs as a random effect (Little et al. 1996). The analysis yields a $t$ statistic. If a dependent variable represents a PTSD risk factor, the model predicts a significant Diagnosis main effect in the absence of a Diagnosis $\times$ Exposure interaction. If a dependent variable represents a traumatically-acquired PTSD sign, the model predicts a significant Diagnosis $\times$ Exposure interaction.

Follow-up contrasts were performed by means of independent $t$ tests between combat-exposed participants with versus without PTSD and separately for respective (high-risk) unex-posed co-twins of combat-exposed twins with PTSD versus (low-risk) unexposed co-twins of combat-exposed twins without PTSD. Pearson correlations were calculated between the total CAPS scores (PTSD severity) of combat-exposed participants and their own as well as their unexposed brothers' performances on the Cube and Paper Test. Two-tailed $p$ values are reported for all tests.

Finally, a stepwise regression analysis was performed in which hippocampal volume was regressed against IQ, two CVLT measures of verbal declarative memory (General Learning, Response Discrimination) found to differentiate PTSD and non-PTSD subjects (Gilbertson $e t$ $a l .2006)$, and the Cube and Paper Test. A significance level of .15 was employed as the criterion for model entry.

\section{Results}

\section{Demographics and Clinical Characteristics}

Group mean demographic data and statistical comparisons appear in Table 1. No significant main effects or interactions were found for age or education. Combat-exposed veterans with PTSD reported significantly higher levels of combat exposure and PTSD symptom severity (total CAPS score), relative to combat-exposed veterans with no history of PTSD. Lifetime alcohol abuse symptoms (MAST) showed a strong Diagnosis $\times$ Exposure interaction, revealing that combat-exposed veterans with PTSD reported more severe alcohol histories than both their unexposed brothers and the non-PTSD twin pair members (both exposed and unexposed). Although the Diagnosis $\times$ Exposure interaction failed to reach statistical significance for number of traumatic lifetime events (non-combat related), significant main effects for both Diagnosis and Exposure were found. The PTSD combat veterans reported more of these than non-PTSD combat veterans $[\mathrm{ExP}+>\mathrm{ExP}-: t(35)=2.6, p=.013]$ and more events than their own unexposed co-twins [ExP+> UxP+: $t(14)=2.5, p=.028]$. No significant difference was found between $\mathrm{UxP}+$ and $\mathrm{UxP}-$ groups $[t(36)=1.24, p=.224]$. We have previously reported in this sample (Gilbertson et al. 2006) that the combat veterans with PTSD demonstrated significantly elevated histories $(p<.05)$ of alcohol and drug use disorders, major depression, and psychotropic medication use relative to both their own twin brothers as well as combat veterans without PTSD (and their twin brothers). Furthermore, the unexposed brothers of combat veterans with versus without PTSD did not differ on any of these comorbidities ( $p>$. 50). We examined the history of head injuries and found the same pattern. The PTSD combat 
veterans reported more head injury than their identical twins (61\% vs. $27 \%$; McNemar's Test: $p<.05)$ and non-PTSD combat veterans (61\% vs. 18\%; Fischer's Exact Test: $p<.01)$. Unexposed brothers of combat veterans with versus without PTSD did not differ in head-injury history (27\% vs. 22\%; Fisher's Exact Test: $p>$.70). Seventy-two percent of reported head injuries involved loss of consciousness (no significant differences between groups), $90 \%$ of which were a "few seconds to few minutes" in duration.

\section{Contextual Cue Processing}

Group Comparisons-On the Cube and Paper Test, a significant Diagnosis main effect [ $t$ $(39)=2.78, p=.008]$ was found in the absence of either a Combat Exposure main effect [ $t$ $(40)=1.13, p=.263]$ or a Diagnosis $\times$ Exposure interaction $[t(39)=.26, p=.797]$. As shown in Figure 2, PTSD combat veterans $(\mathrm{M}=8.7$ errors, $\mathrm{SD}=4.7)$ and their unexposed brothers $(\mathrm{M}=8.0$ errors, $\mathrm{SD}=6.1)$ demonstrated more errors in configural cue processing than nonPTSD combat veterans $(\mathrm{M}=5.3$ errors, $\mathrm{SD}=4.1)$ and their unexposed brothers $(\mathrm{M}=4.2$ errors, $\mathrm{SD}=4.4$ ). The effect size (Cohen's d) for the Diagnosis main effect was .89, compared with . 36 and .08 for Exposure main effect and Diagnosis $\times$ Exposure interaction, respectively. Follow-up contrasts revealed that PTSD combat veterans made more errors than non-PTSD combat veterans $[\mathrm{ExP}+>\operatorname{ExP}-: t(39)=2.43, p=.020]$, and a comparable relationship existed between their respective high-risk and low-risk co-twins [UxP+ > UxP-: $t(39)=2.30, p=$. 027].

The Diagnosis main effect remained significant after controlling for lifetime alcohol abuse [MAST; $t(45.5)=2.31, p=.026]$. The diagnosis main effect also remained marginally significant after controlling for an IQ-based measure of visuospatial functioning [WAIS-R Block Design; $t(38.9)=1.98, p=.054]$ as well as in a model simultaneously controlling for all available visuospatial measures [FRT, VOSP, Block Design; $t(39)=2.02, p=.050$ ]. The diagnosis main effect failed to maintain significance when controlling for general verbal functioning [WAIS-R Vocabulary; $t(40.9)=1.35, p=.186]$ or overall estimated IQ [t(41.4) $=$ $1.00, p=.325]$.

Correlations With PTSD Symptom Severity and Combat Severity-Severity of PTSD symptomatology (total CAPS score) in combat-exposed veterans was positively correlated with both their own Cube and Paper Test errors $[r(41)=.40, p=.010]$ as well as those of their combat-unexposed brothers $[r(41)=.31, p=.046]$. Errors in the Cube and Paper Test by combat-exposed veterans were positively correlated with amount of combat exposure $[r(41)=.33, p=.036]$. The relationship between Cube and Paper Test performance and PTSD severity fell to a marginal level after controlling for amount of combat exposure [partial; $r(41)$ $=.26, p=.104]$. However, interpretation of the relationship is complicated by the highly confounded relationship between PTSD severity and amount of combat exposure $[r(41)=.64$, $p<.0001]$.

\section{Regression Analysis of Hippocampal Volume and Cognitive Measures-A}

stepwise regression analysis was performed regressing total MRI hippocampal volume against estimated IQ, two measures of CVLT verbal memory function (General Learning, Response Discrimination), and the Cube and Paper Test. The Cube and Paper Test performance was found to be the only predictor of total hippocampal volume $[F=6.23, p=.015]$; no other variable entered into the model at a significance level $<p=.15$. Furthermore, when IQ and memory measures were forced first into the regression model, the addition of Cube and Paper Test performance was significant [Cube and Paper: $F=3.98, p=.050$; IQ: $F=.02, p=.901$; General Learning: $F=.04, p=.848$; Response Discrimination: $F=.60, p=.439]$. Configural cue processing alone accounted for $8.0 \%$ of total hippocampal volume variance compared with $3.6 \%$ of hippocampal volume variance explained by the combined variance of IQ and 
declarative memory. The full model containing all four cognitive measures accounted for $8.9 \%$ of total hippocampal volume variance. Finally, when alcohol history and either total grey matter volume or total amygdala volume were also added simultaneously to the model, Cube and Paper Test performance continued to be the only significant predictor of hippocampal volume (however, in the case of adding total grey matter volume to the model, both Cube and Paper Test and total grey matter volume predicted hippocampal volume, with Cube and Paper Test somewhat attenuated [i.e., $p=.068]$ ).

\section{Discussion}

The current study provides evidence supporting the presence of allocentric spatial processing deficits in chronic PTSD. Although previous studies have not consistently documented general visuospatial impairment in PTSD, prior investigations have largely employed "egocentric" (in reference to body-midline) rather than "allocentric" (related to configural relationships among distal stimuli) tasks. The specific nature of this spatial deficit was demonstrated in the current study by the fact that differences in allocentric performance were maintained even after controlling for multiple measures of general visuospatial ability.

Of additional interest is the fact that the difference observed in allocentric spatial processing between PTSD and non-PTSD combat veterans in this study seems to represent a pre-existing familial risk factor as evidenced by the presence of a comparable deficit in their identical cotwin brothers who had neither combat-exposure nor PTSD. These "high risk" co-twins demonstrated significantly impaired performance relative to the non-PTSD combat veterans and their "low risk" unexposed co-twins. Furthermore, the severity of PTSD symptomatology in combat-exposed participants was predicted not only by their own performance on the Cube and Paper Test but also by the performance of their unexposed identical co-twins. We have previously demonstrated in this sample (Gilbertson et al. 2002, 2006) that the deficits observed in the familial vulnerability pattern cannot be explained by comorbidity confounds (e.g., alcohol/substance abuse, depression) or medication use. In the current study, we also extend this finding to history of head injury. The ExP+ twins and their UxP+co-twins differ in these comorbid conditions (i.e., UxP+ co-twins do not show elevated comorbid conditions, history of head injury, or medication use), yet the ExP+ and UxP+ co-twins show similar performance in the dependent variable of interest, in this case allocentric spatial processing.

When placed in a prediction model alongside measures of IQ and verbal declarative memory, Cube and Paper Test performance was the best (and only) predictor of hippocampal volume in study participants. We found no significant relationship between hippocampal volume and the measures of verbal declarative memory and IQ that differentiated PTSD and non-PTSD veterans in this sample (Gilbertson et al. 2006). This is the first study to provide evidence that the role of hippocampal morphology in PTSD might be related to allocentric spatial processing. It should be noted, however, that our findings do not clearly establish the overall specificity of the hippocampus in mediating this task, and non-hippocampal regions (e.g., posterior parietal, orbitofrontal) might be expected to impact performance as well. In animal studies, Corwin et al. (1994) demonstrated the potential relevance of orbitofrontal cortex to allocentric processing, although human studies have been less compelling (Galati et al. 2000; Neggers et al. 2006). The fact that performance on the Cube and Paper Test continued to predict hippocampal volume even after adding amygdala volume or total grey matter volume to the regression model is suggestive of a prominent role for the hippocampus. However, it would be premature to rule out the impact of other brain regions, and more sophisticated allocentric tasks should be employed in future studies.

Configural cue processing deficits provide support, albeit of a preliminary nature, for what we believe to be an intuitively appealing, alternative model of hippocampal function in PTSD. 
This model, which has been broadly suggested by Davidson et al. (Davidson 2000; Davidson et al. 2000), asserts that the role of the hippocampus in psychopathological disorders such as PTSD might involve deficits in the ability to encode context (e.g., patterns of environmental cues) to regulate emotional responses. Building on the general role attributed to the hippocampus in the spatial processing of environmental cues (e.g., "spatial map" theory of O'Keefe and Nadel [1978]), numerous studies have begun to more specifically delineate the contribution of the hippocampus in shaping fear acquisition and extinction via contextual processing (Anagnostaras et al. 1995; Corcoran and Maren 2001; Frankland et al. 1998; Phillips and LeDoux 1994; Winocur 1997). Background environmental cues might be important in "setting the scene" for interpreting the fear relevance of a given CS (Schmajuk and Buhusi 1997; i.e., context-appropriate fear responding). Whereas the amygdala has been shown to play a critical role in the mediation of discrete CS-CR pairings, animal studies have demonstrated that lesions of the hippocampus (particularly the dorsal hippocampus) prevent or alter the acquisition and expression of many forms of contextual fear conditioning.

In the presence of compromised hippocampal capacity, animals might be less proficient in their ability to encode complex background environment to suppress context-inappropriate conditioned responses. As noted previously, the hippocampus has been shown to be especially relevant to the mediation of allocentric as opposed to egocentric spatial cues (Burgess et al. 1999), a function that makes it ideal for complex, configural contextual processing. Other nonhippocampal brain regions can support the limited processing of context at a more elemental or individual cue level. However, an intact hippocampus seems to retain a relatively unique capacity for integrating multiple individual elements into a relational whole while at the same time suppressing more elemental cue processing by other brain regions (Driscoll et al. 2005; Maren 2001; Sutherland et al. 1989). Reduced hippocampal capacity would therefore be expected to result in a relative over-reliance on contextual conditioning to simple, elemental cues mediated by non-hippocampal brain regions. A larger or more functional hippocampus, which monitors the presence and configural relationship of multiple cues within an environment and not merely the presence of individual or isolated cues, might better discriminate whether a particular contextual environment appropriately signals the relevance of a conditioned fear response.

The potential significance of hippocampus-based, allocentric processing of contextual cues for the pathophysiology of PTSD is perhaps best made evident in animal studies of extinction (i.e., loss of conditioned fear response when a CS is repeatedly presented in the absence of the US). It is generally accepted that stimulus-response conditioning has relative permanency (i.e., extinction does not destroy or cause an "unlearning" of the original conditioned response) (Bouton 2002; Rescorla 2001). Rather, inhibitory processes can temporarily or situationally suppress expression of the $\mathrm{CR}$, resulting in extinction. One such inhibitory process contributing to extinction is environmental context (Bouton 1993, 2000). In an important demonstration of this process in relation to hippocampal morphology, Frankland et al. (1998) found that animals that received hippocampal lesions before fear conditioning were unable to fully differentiate aversive versus non-aversive contextual environments and failed to effectively extinguish conditioned fear responses in a new chamber that had no history of aversive conditioning. The mere presence of isolated cues associated with the original aversive chamber seemed capable of signaling the relevance of a fear response in the "safe" chamber. Frankland et al. replicated this result in mice with genetic mutations associated with compromised hippocampal function. We propose that, consistent with this formulation, smaller hippocampal volume before trauma exposure might lead to failures in context-appropriate extinction of conditioned emotional responses, resulting in unremitting PTSD symptomatology.

In the clinical literature, the term "contextualization" has been coined to describe a patient's capacity to discriminate between "then" (original traumatic environment) and "now" (current 
environment), contributing to the persistence of PTSD-related symptoms (Ehlers and Clark 2000; Foa and Rothbaum 1998). The hippocampus might represent a biological substrate for this process, and the inability to adequately engage allocentric processing of contextual information might provide a model for understanding the persistent nature of conditioned emotional responses in chronic PTSD patients after removal from the original traumatic environment. The well-described re-experiencing symptoms of PTSD as documented in the DSM-IV (American Psychiatric Association 1994; e.g., "physiological reactivity on exposure to internal or external cues" [criterion $\mathrm{B}(5)$ ]) would be predicted by impaired hippocampal capacity to decode configural arrays of cues that would normally suppress inappropriate fear responses to the mere presence of isolated individual cues. Thus, for example, a combat veteran with unremitting PTSD who is no longer in the combat field might experience significant conditioned physiological and emotional responses when exposed to a single cue (e.g., sound of a helicopter, smell of gun powder, sight of a person who shares physical features with the former enemy, etc.) even though this cue exists in an array of complex cues that otherwise defines the context as safe.

A number of limitations to the current study should be acknowledged. We employed a rather simple paper-and-pencil task in our assessment of "allocentric" spatial processing. More complex procedures for measuring allocentric spatial processing with three-dimensional space or virtual reality (Astur et al. 2002; Driscoll et al. 2003) should be employed in future studies. Future studies employing psychophysiological conditioning and extinction protocols with human participants diagnosed with PTSD will also be required to more fully validate the model proposed here. Future studies will also require the inclusion of both remitted and unremitted populations of PTSD patients to more clearly establish a relationship between the course or chronicity of PTSD and allocentric processing.

An additional caution should be raised regarding the potentially confounding factor of overall intelligence. Cube and Paper Test differences did not maintain statistical significance when the covariates of verbal and overall IQ were taken into account. As described by Miller and Chapman (2001), the interpretation of covariance analyses must be cautious when the covariate (i.e., IQ) differs between experimental groups (i.e., PTSD vs. non-PTSD). "Controlling" for differences in IQ under these circumstances can statistically underestimate the true difference and significance level of the dependent measure. Nonetheless, our findings can not definitively rule out the possibility that Cube and Paper performance reflects overall poorer cognitive functioning. A number of factors potentially mitigate this concern. First, the viewpoint that Cube and Paper performance is not simply synonymous with IQ is supported by the observation that the Cube and Paper task was predictive of hippocampal volume whereas IQ was not (likewise, Cube and Paper performance was predictive of hippocampal volume even when IQ was accounted for). Furthermore, not all aspects of IQ significantly attenuated the effects of Cube and Paper test performance (i.e., it remained significant when "controlling" for nonverbal IQ). Finally, the finding that other cognitive tasks were highly correlated with IQ in our sample (e.g., VOSP, FRT) yet did not differentiate PTSD and non-PTSD subjects (Gilbertson et al. 2006) again mitigates against the notion that IQ alone is the relevant factor.

In recent years, neuroimaging studies have yielded an impressive array of findings uncovering significant brain-based differences associated with PTSD. These exciting developments have usefulness to the degree that coherent links can be established to the specific clinical phenomenology of interest. Findings of the current study suggest specific mechanisms by which hippocampal morphology and function might mediate particular clinical features of chronic PTSD. These findings further point to the potential importance of examining preexisting, brain-based cognitive differences that might impact how a traumatic event is processed and therefore affect the severity and/or longevity of associated symptoms. Ultimately, the elucidation of these brain-based cognitive processes might guide the 
development of new behavioral treatment strategies (e.g., remediation of contextual cue deficits) that might improve the treatment of intractable or treatment-resistant PTSD.

\section{Acknowledgments}

This work was supported by Department of Veterans Affairs Merit Review Grants (MWG, SPO), USPHS Grant R01MH54636 (RKP), and USPHS Grant K02-MH01110 (MES).

We would like to thank M. Macklin, K. Sheldon, H. Croteau, and the VA Cooperative Studies VET Registry (M.E. Vitek, K. Bukowski, R. Havlicek, T. Colton, W.E. Nance, R.S. Paffenbarger Jr., M.M. Weissman, and R.R. Williams) for their assistance in this project. We gratefully acknowledge the participation of the veterans and their twin brothers. Without their contribution this research would not have been possible.

\section{References}

American Psychiatric Association. Diagnostic and Statistical Manual of Mental Disorders. Vol. 4th ed.. American Psychiatric Association; Washington, DC: 1994.

Anagnostaras SG, Maren S, Fanselow MS. Scopolamine selectively disrupts the acquisition of contextual fear conditioning in rats. Neurobiol Learn Mem 1995;64:191-194. [PubMed: 8564372]

Astur RS, Taylor LB, Mamelak AN, Philpott L, Sutherland RJ. Humans with hippocampus damage display severe spatial memory impairments in a virtual Morris water task. Behav Brain Res 2002;132:77-84. [PubMed: 11853860]

Beers SR, De Bellis MD. Neuropsychological function in children with maltreatment-related posttraumatic stress disorder. Am J Psychiatry 2002;159:483-486. [PubMed: 11870018]

Benton, AL.; Van Allen, MW. Test of Facial Recognition: Neurosensory Center Publication No. 287. University of Iowa; Iowa City, Iowa: 1973.

Blake DD, Weathers FW, Nagy LM, Kaloupek DG, Gusman FD, Charney DS, Keane TM. The development of a Clinician-Administered PTSD Scale. J Trauma Stress 1995;8:75-90. [PubMed: 7712061]

Bonne O, Brandes D, Gilboa A, Gomori JM, Shenton ME, Pitman RK, Shalev AY. Longitudinal MRI study of hippocampal volume in trauma survivors with PTSD. Am J Psychiatry 2001;158:1248-1251. [PubMed: 11481158]

Bouton ME. Context, time, and memory retrieval in the interference paradigms of Pavlovian learning. Psychol Bull 1993;114:80-99. [PubMed: 8346330]

Bouton ME. A learning theory perspective on lapse, relapse, and the maintenance of behavior change. Health Psychol 2000;19:57-63. [PubMed: 10709948]

Bouton ME. Context, ambiguity, and unlearning: Sources of relapse after behavioral extinction. Biol Psychiatry 2002;52:976-986. [PubMed: 12437938]

Bremner JD, Randall P, Scott TM, Bronen RA, Seibyl JP, Southwick SM, et al. MRI-based measurement of hippocampal volume in patients with combat-related posttraumatic stress disorder. Am $\mathrm{J}$ Psychiatry 1995a;152:973-981. [PubMed: 7793467]

Bremner JD, Randall P, Scott TM, Capelli S, Delaney R, McCarthy G, Charney DS. Deficits in shortterm memory in adult survivors of childhood abuse. Psychiatry Res 1995b;59:97-107. [PubMed: 8771224]

Bremner JD, Randall P, Vermetten E, Staib L, Bronen RA, Mazure C, et al. Magnetic resonance imagingbased measurement of hippocampal volume in posttraumatic stress disorder related to childhood physical and sexual abuse-a preliminary report. Biol Psychiatry 1997;41:23-32. [PubMed: 8988792]

Bremner JD, Scott TM, Delaney RC, Southwick SM, Mason JW, Johnson DR, et al. Deficits in shortterm memory in posttraumatic stress disorder. Am J Psychiatry 1993;150:1015-1019. [PubMed: 8317569]

Burgess, N.; Jeffrey, K.; O'Keefe, J. Integrating hippocampal and parietal functions: A spatial point of view.. In: Burgess, N.; Jeffrey, K.; O'Keefe, J., editors. The Hippocampal and Parietal Foundations of Spatial Cognition. Oxford University Press; Oxford: 1999. 
Carrion VG, Weems CF, Eliez S, Patwardhan A, Brown W, Ray RD, Reiss AL. Attenuation of frontal asymmetry in pediatric posttraumatic stress disorder. Biol Psychiatry 2001;50:943-951. [PubMed: 11750890]

Corcoran KA, Maren S. Hippocampal inactivation disrupts contextual retrieval of fear memory after extinction. J Neurosci 2001;21:1720-1726. [PubMed: 11222661]

Corwin JV, Fussinger M, Meyer RC, King VR, Reep RL. Bilateral destruction of the ventrolateral orbital cortex produces allocentric but not egocentric spatial deficits in rats. Behav Brain Res 1994;61:7986. [PubMed: 8031498]

Davidson RJ. Cognitive neuroscience needs affective neuroscience (and vice versa). Brain Cogn 2000;42:89-92. [PubMed: 10739607]

Davidson RJ, Jackson DC, Kalin NH. Emotion, plasticity, context, and regulation: Perspectives from affective neuroscience. Psychol Bull 2000;126:890-909. [PubMed: 11107881]

De Bellis MD, Hall J, Boring AM, Frustaci K, Moritz G. A pilot longitudinal study of hippocampal volumes in pediatric maltreatment-related posttraumatic stress disorder. Biol Psychiatry 2001;50:305-309. [PubMed: 11522266]

De Bellis MD, Keshavan MS, Clark DB, Casey BJ, Giedd JN, Boring AM, et al. A.E. Bennett Research Award. Developmental traumatology. Part II: Brain development. Biol Psychiatry 1999;45:12711284. [PubMed: 10349033]

Delis, DC.; Kramer, JH.; Kaplan, E.; Ober, BA. California Verbal Learning Test-Adult Version. The Psychological Corporation; New York: 1987.

Driscoll I, Hamilton DA, Petropoulos H, Yeo RA, Brooks WM, Baumgartner RN, Sutherland RJ. The aging hippocampus: Cognitive, biochemical and structural findings. Cereb Cortex 2003;13:13441351. [PubMed: 14615299]

Driscoll I, Howard SR, Prusky GT, Rudy JW, Sutherland RJ. Seahorse wins all races: Hippocampus participates in both linear and non-linear visual discrimination learning. Behav Brain Res 2005;164:29-35. [PubMed: 16024101]

Ehlers A, Clark DM. A cognitive model of posttraumatic stress disorder. Behav Res Ther 2000;38:319345. [PubMed: 10761279]

Eisen S, Neuman R, Goldberg J, Rice J, True W. Determining zygosity in the Vietnam Era Twin Registry: An approach using questionnaires. Clin Genet 1989;35:423-432. [PubMed: 2736790]

First, MB.; Spitzer, RL.; Gibbon, M.; Williams, JBW. Structured Clinical Interview for Axis I DSM-IV Disorders, Version 2.0. Biometrics Research Department; New York: 1994.

Foa, EB.; Rothbaum, BO. Cognitive-Behavior Therapy for PTSD. The Guilford Press; New York: 1998. Treating the Trauma of Rape..

Frankland PW, Cestari V, Filipkowski RK, McDonald RJ, Silva AJ. The dorsal hippocampus is essential for context discrimination but not for contextual conditioning. Behav Neurosci 1998;112:863-874. [PubMed: 9733192]

French, JW.; Ekstrom, RT.; Price, LA. Kit of Reference Tests for Cognitive Factors. Educational Testing Service; Princeton, New Jersey: 1963.

Galati G, Lobel E, Guiseppe V, Berthoz A, Pizzamiglio L, Le Bihan D. The neural basis of egocentric and allocentric coding of space in humans: A functional magnetic resonance study. Exp Brain Res 2000;133:156-164. [PubMed: 10968216]

Gilbertson MW, Gurvits TV, Lasko NB, Orr SP, Pitman RK. Multivariate assessment of explicit memory function in combat veterans with posttraumatic stress disorder. J Trauma Stress 2001;14:413-432. [PubMed: 11469166]

Gilbertson MW, Gurvits TV, Lasko NB, Pitman RK. Neuropsychological assessment of Vietnam combat veterans with and without PTSD. Ann N Y Acad Sci 1997;821:476-479. [PubMed: 9238233]

Gilbertson MW, Paulus LA, Williston SK, Gurvits TV, Lasko NB, Shenton ME, et al. Neurocognitive function in monozygotic twins discordant for combat exposure: Relationship to posttraumatic stress disorder. J Abnorm Psychol 2006;115:484-495. [PubMed: 16866589]

Gilbertson MW, Shenton ME, Ciszewski A, Kasai K, Lasko NB, Orr SP, Pitman RK. Smaller hippocampal volume predicts pathologic vulnerability to psychological trauma. Nat Neurosci 2002;5:1242-1247. [PubMed: 12379862] 
Golier J, Yehuda R, Lupien SJ, Harvey PD, Grossman R, Elkin A. Memory performance in Holocaust survivors with posttraumatic stress disorder. Am J Psychiatry 2002;159:1682-1688. [PubMed: 12359673]

Gurvits TV, Gilbertson MW, Lasko NB, Tarhan AS, Simeon D, Macklin ML, et al. Neurologic soft signs in chronic posttraumatic stress disorder. Arch Gen Psychiatry 2000;57:181-186. [PubMed: 10665621]

Gurvits TV, Lasko NB, Repak AL, Metzger LJ, Orr SP, Pitman RK. Performance on visuospatial copying tasks in individuals with chronic posttraumatic stress disorder. Psychiatry Res 2002;112:263-268. [PubMed: 12450636]

Gurvits TV, Shenton ME, Hokama H, Ohta H, Lasko NB, Gilbertson MW, et al. Magnetic resonance imaging study of hippocampal volume in chronic, combat-related posttraumatic stress disorder. Biol Psychiatry 1996;40:1091-1099. [PubMed: 8931911]

Halpern, DF. Sex Differences in Cognitive Abilities. Lawrence Erlbaum; Hillsdale, New Jersey: 1986.

Holland PC, Bouton ME. Hippocampus and context in classical conditioning. Curr Opin Neurobiol 1999;9:195-202. [PubMed: 10322181]

Horner MD, Hamner MB. Neurocognitive functioning in posttraumatic stress disorder. Neuropsychol Rev 2002;12:15-30. [PubMed: 12090717]

Incisa della Rocchetta A, Samson S, Ehrle N, Denos M, Hasboun D, Baulac M. Memory for visuospatial location following selective hippocampal sclerosis: The use of different coordinate systems. Neuropsychology 2004;18:15-28. [PubMed: 14744184]

Janes GR, Goldberg J, Eisen SA, True WR. Reliability and validity of a combat exposure index for Vietnam era veterans. J Clin Psychol 1991;47:80-86. [PubMed: 2026782]

Kessler RC, Sonnega A, Bromet E, Hughes M, Nelson CB. Posttraumatic stress disorder in the National Comorbidity Survey. Arch Gen Psychiatry 1995;52:1048-1060. [PubMed: 7492257]

Koenen KC, Stellman JM, Stellman SD, Sommer JF Jr. Risk factors for course of posttraumatic stress disorder among Vietnam veterans: A 14-year follow-up of American Legionnaires. J Consult Clin Psychol 2003;71:980-986. [PubMed: 14622073]

Little, RC.; Milliken, GA.; Stroup, WW.; Wolfinger, RD. SAS System for Mixed Models. SAS Institute; Cary, North Carolina: 1996.

Maren S. Neurobiology of Pavlovian fear conditioning. Annu Rev Neurosci 2001;24:897-931. [PubMed: 11520922]

Maren S, Aharonov G, Fanselow MS. Neurotoxic lesions of the dorsal hippocampus and Pavlovian fear conditioning in rats. Behav Brain Res 1997;88:261-274. [PubMed: 9404635]

McDonald RJ, Ko CH, Hong NS. Attenuation of context-specific inhibition on reversal learning of a stimulus-response task in rats with neurotoxic hippocampal damage. Behav Brain Res 2002;136:113126. [PubMed: 12385796]

McGee MG. Human spatial abilities: Psychometric studies and environmental, genetic, hormonal, and neurological influences. Psychol Bull 1979;86:889-918. [PubMed: 386403]

Miller GA, Chapman JP. Misunderstanding analysis of covariance. J Abnorm Psychol 2001;110:40-48. [PubMed: 11261398]

Moses SN, Sutherland RJ, McDonald RJ. Differential involvement of amygdala and hippocampus in responding to novel objects and contexts. Brain Res Bull 2002;58:517-527. [PubMed: 12242105]

Neggers SFW, Van der Lubbe RHJ, Ramsey NF, Postma A. Interactions between ego- and allocentric neuronal representations of space. Neuro-Image 2006;31:320-331. [PubMed: 16473025]

O'Keefe, J.; Nadel, L. The Hippocampus as a Cognitive Map. Oxford University Press; Oxford: 1978.

Orr SP, Metzger LJ, Lasko NB, Macklin ML, Hu FB, Shalev AY, Pitman RK. Physiologic responses to sudden, loud tones in monozygotic twins discordant for combat exposure: Association with posttraumatic stress disorder. Arch Gen Psychiatry 2003;60:283-288. [PubMed: 12622661]

Orr SP, Pitman RK, Lasko NB, Herz LR. Psychophysiological assessment of posttraumatic stress disorder imagery in World War II and Korean combat veterans. J Abnorm Psychol 1993;102:152-159. [PubMed: 8436691]

Phillips RG, LeDoux JE. Differential contribution of amygdala and hippocampus to cued and contextual fear conditioning. Behav Neurosci 1992;106:274-285. [PubMed: 1590953] 
Phillips RG, LeDoux JE. Lesions of the dorsal hippocampal formation interfere with background but not foreground contextual fear conditioning. Learn Mem 1994;1:34-44. [PubMed: 10467584]

Rescorla RA. Retraining of extinguished Pavlovian stimuli. J Exp Psychol Anim Behav Process 2001;27:115-124. [PubMed: 11296487]

Schmajuk NA, Buhusi CV. Stimulus configuration, occasion setting, and the hippocampus. Behav Neurosci 1997;111:235-257. [PubMed: 9106665]appendix 258

Selden NR, Everitt BJ, Jarrard LE, Robbins TW. Complementary roles for the amygdala and hippocampus in aversive conditioning to explicit and contextual cues. Neuroscience 1991;42:335-350. [PubMed: 1832750]

Selzer ML. The Michigan alcoholism screening test: The quest for a new diagnostic instrument. Am J Psychiatry 1971;127:1653-1658. [PubMed: 5565851]

Shenton ME, Kikinis R, Jolesz FA, Pollak SD, LeMay M, Wible CG, et al. Abnormalities of the left temporal lobe and thought disorder in schizophrenia. A quantitative magnetic resonance imaging study. N Engl J Med 1992;327:604-612. [PubMed: 1640954]

Squire LR. Memory and the hippocampus: A synthesis from findings with rats, monkeys, and humans. Psychol Rev 1992;99:195-231. [PubMed: 1594723]

Stein MB, Koverola C, Hanna C, Torchia MG, McClarty B. Hippocampal volume in women victimized by childhood sexual abuse. Psychol Med 1997;27:951-959. [PubMed: 9234472]

Sutherland RJ, McDonald RJ, Hill CR, Rudy JW. Damage to the hippocampal formation in rats selectively impairs the ability to learn cue relationships. Behav Neural Biol 1989;52:331-356. [PubMed: 2590146]

Vasterling JJ, Brailey K, Constans JI, Sutker PB. Attention and memory dysfunction in posttraumatic stress disorder. Neuropsychology 1998;12:125-133. [PubMed: 9460740]

Vasterling JJ, Brailey K, Sutker PB. Olfactory identification in combat-related posttraumatic stress disorder. J Trauma Stress 2000;13:241-253. [PubMed: 10838673]

Vasterling JJ, Duke LM, Brailey K, Constans JI, Allain AN Jr, Sutker PB. Attention, learning, and memory performances and intellectual resources in Vietnam veterans: PTSD and no disorder comparisons. Neuropsychology 2002;16:5-14. [PubMed: 11853357]

Villarreal G, Hamilton DA, Petropoulos H, Driscoll I, Rowland LM, Griego JA, et al. Reduced hippocampal volume and total white matter volume in posttraumatic stress disorder. Biol Psychiatry 2002;52:119-125. [PubMed: 12114003]

Warrington, EK.; James, M. The Visual Object and Space Perception Battery. Thames Valley Test Company; Bury St. Edmunds, United Kingdom: 1991.

Wechsler, D. Wechsler Adult Intelligence Scale-Revised. The Psychological Corporation; New York: 1987.

Winocur G. Hippocampal lesions alter conditioning to conditional and contextual stimuli. Behav Brain Res 1997;88:219-229. [PubMed: 9404631]

Yehuda R, Keefe RS, Harvey PD, Levengood RA, Gerber DK, Geni J, Siever LJ. Learning and memory in combat veterans with posttraumatic stress disorder. Am J Psychiatry 1995;152:137-139. [PubMed: 7802106]

Zola-Morgan S, Squire LR. Neuroanatomy of memory. Annu Rev Neurosci 1993;16:547-563. [PubMed: 8460903] 

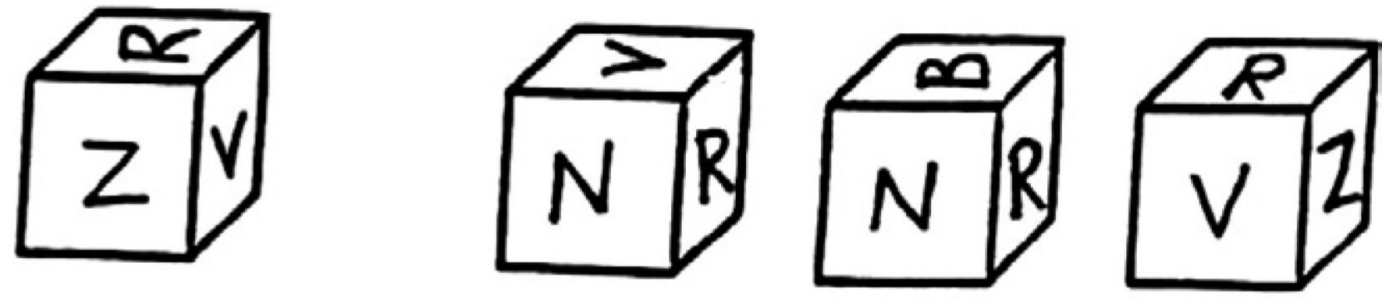

A

B

C
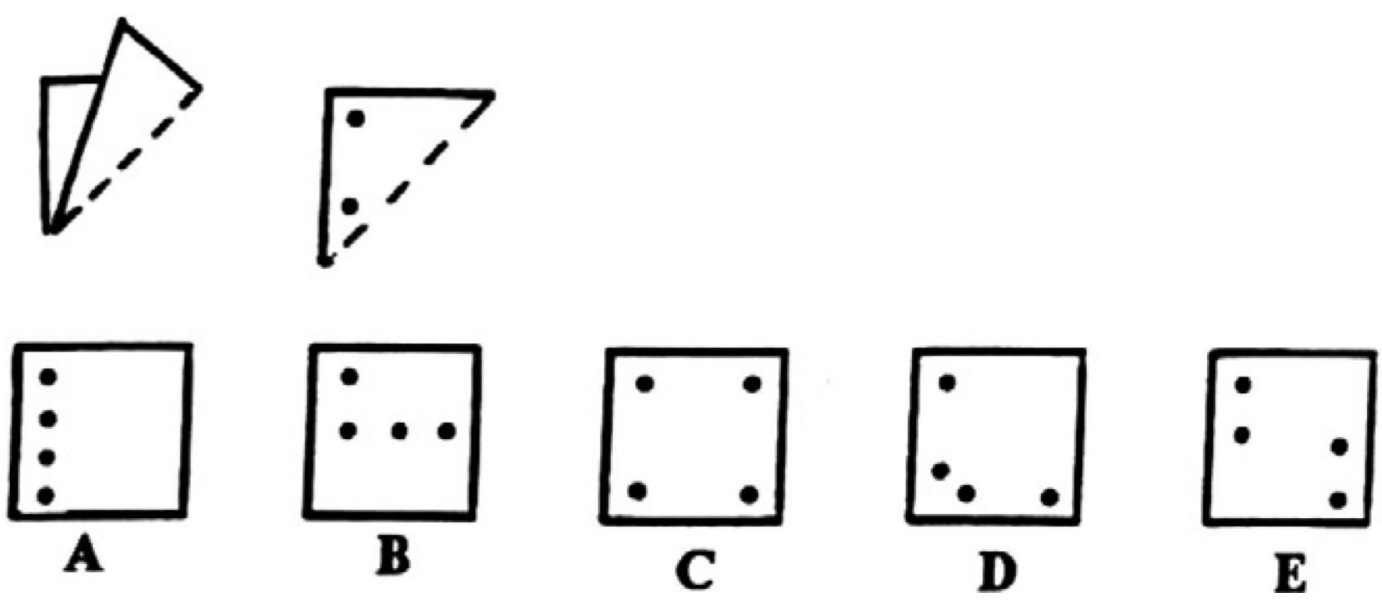

Figure 1.

Sample items from Cube \& Paper Test. 


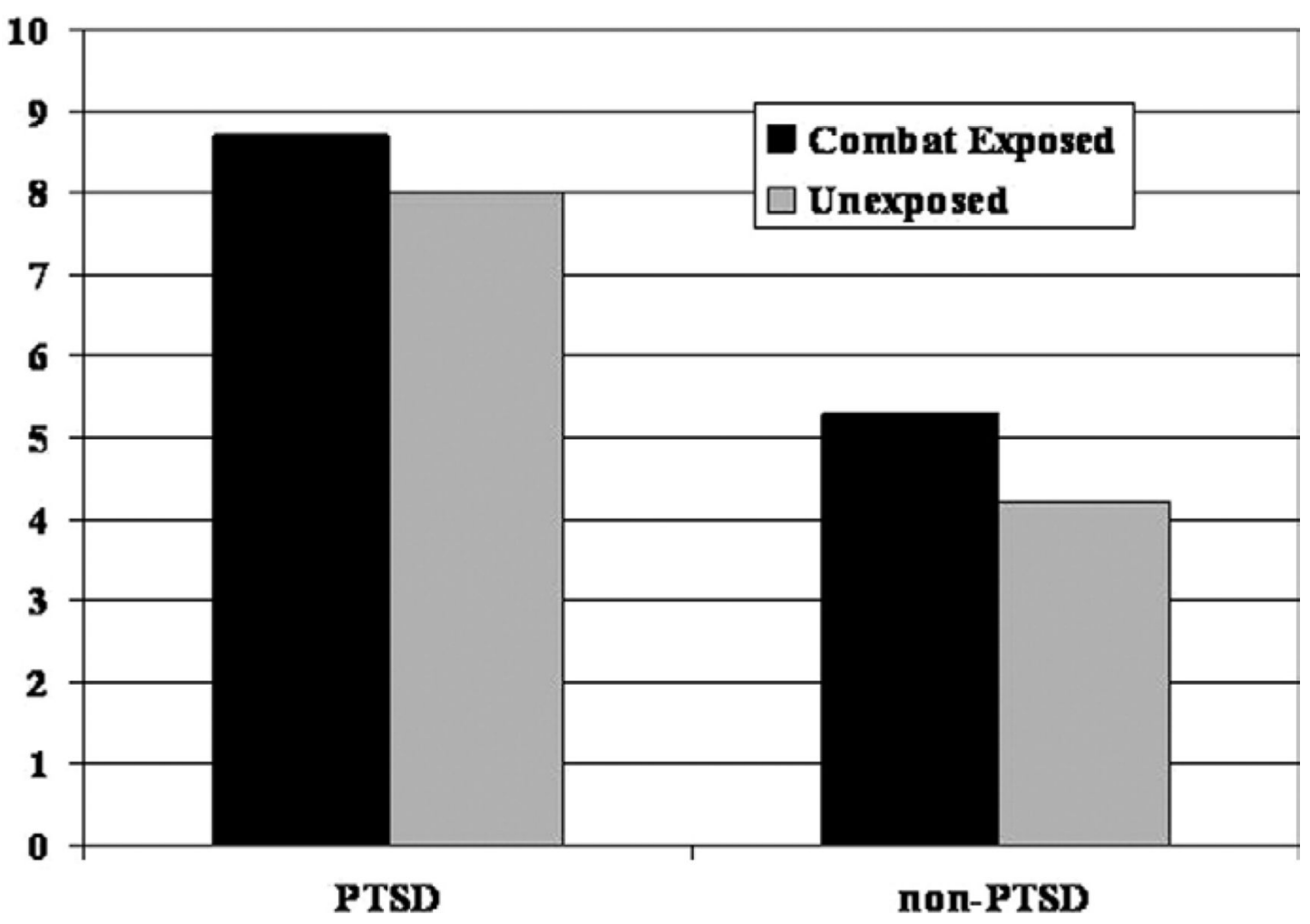

Figure 2.

Total errors on Cube \& Paper Test. 


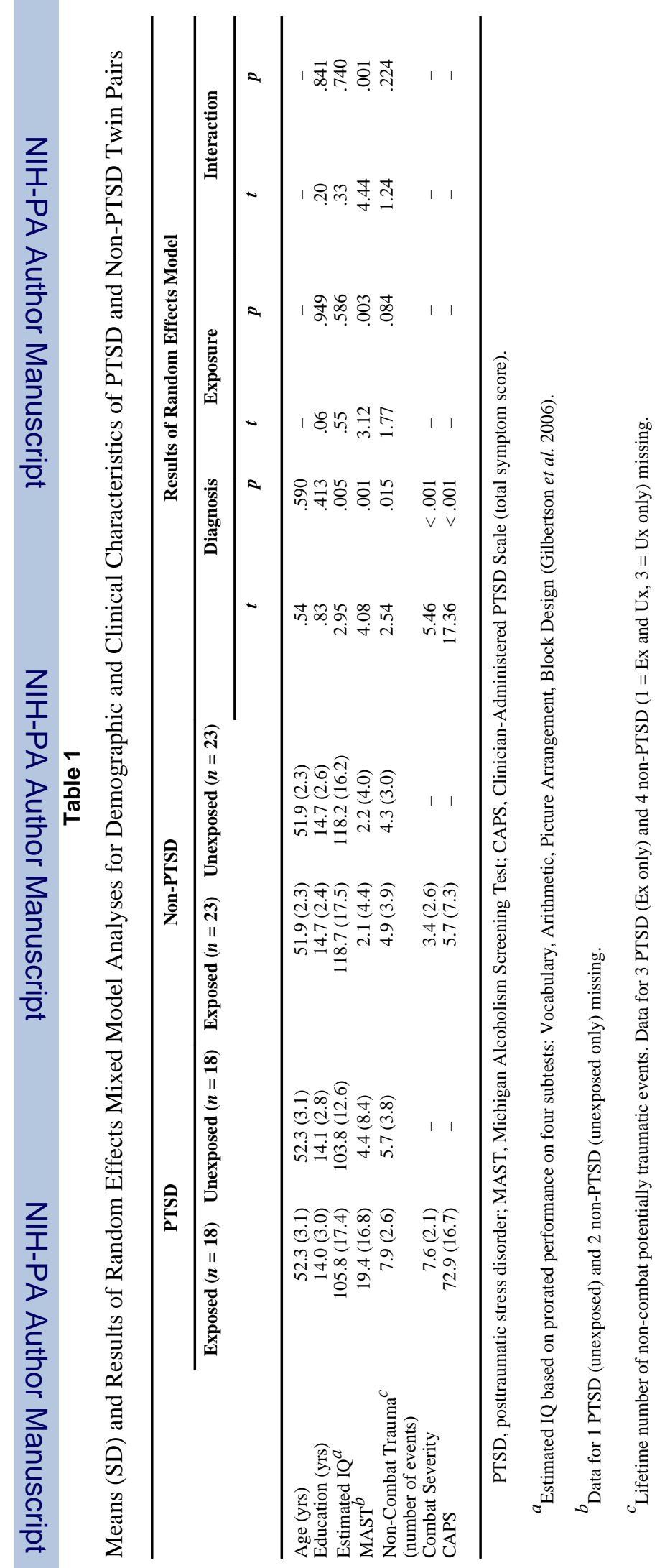

Biol Psychiatry. Author manuscript; available in PMC 2009 October 27. 